\title{
A BMJ for the United States
}

\author{
New US edition of bmj.com launches this week
}

\author{
David Payne editor, bmj.com, Fiona Godlee editor in chief
}

BMJ, London WC1H 9JR, UK

In New York last week David Cameron made history as the first British prime minister to appear on CBS's Late Show with David Letterman.

This week the $B M J$ takes an equally important step (in our view) with the launch of a US edition of bmj.com, the first international general medical journal to "geotarget" in this way.

Each month the journal's website gets more than 368782 visits from US physicians, academic researchers, policymakers, and other healthcare professionals, ${ }^{1}$ a quarter of our overall traffic. From now on they will see a dedicated homepage showing the latest articles of direct relevance to them.

The site's four channels-news, comment, research, and education-will also prioritise content of interest to readers in the United States.

This is an exciting development for the $B M J$, and it forms part of a wider strategy to increase the amount of scholarly and journalistic content from the United States.

To help us achieve that aim, we are strengthening our editorial presence in the US. Jose Merino joins us as US research editor, and he will be working closely with Elizabeth Loder, the journal's clinical epidemiology editor.

Dr Merino will combine his new role with clinical practice as a neurologist with Johns Hopkins Community Physicians in Bethesda, Maryland. Dr Loder has been the BMJ's senior research editor since 2006. Based in Boston, at Brigham and Women's/Faulkner Hospital, she leads the division of headache and pain in the Department of Neurology.

Edward Davies is the BMJ's new US news and comment editor and will be based in New York. Edward will work alongside our established contributors to expand the journal's US news and features output.

These include our regular columnist Douglas Kamerow, a Washington based family doctor and former assistant surgeon general; physicians Lisa Schwartz and Steve Woloshin (coauthors of our successful Not So Stories series); the investigative journalists Jeanne Lenzer and Ray Moynihan; and the policy commentator Shannon Brownlee.

The BMJ's US project began more than a year ago when a routine audit of our articles and weekly podcasts revealed that an increasing number were about US healthcare, particularly as President Obama's planned changes took shape and an outreach program yielded more submissions from US researchers and commentators.

We were also struck by the high volume of US web traffic to our investigative features, all of which had implications for US policymakers and clinicians.

In early 2011 Brian Deer exposed the bogus data behind claims that launched a worldwide scare over the measles, mumps, and rubella (MMR) vaccine. ${ }^{2}$ In July this year Deborah Cohen investigated the links between the sports drinks industry and academia that have helped market the science of hydration. ${ }^{3}$ Previous $B M J$ investigations include how the Food and Drug Administration regulates medical devices and conflicts of interest in guideline committees. ${ }^{45}$

Our first thought was to copy other international titles (such as $\mathrm{CNN}, \mathrm{BBC}$, and the Guardian newspaper) by launching a separate homepage for our US readers. But we decided to go further by launching dedicated research, education, news, and comment channels, where we could showcase articles of relevance to US clinicians and researchers.

This presented some challenges. As an international journal, we didn't want to deprive US readers of articles about healthcare in other countries. Nor did we want to bombard busy US clinicians with stories about the British NHS.

We developed a system of tagging stories which should ensure that those of less relevance to US readers are not displayed. These stories will of course still be available on bmj.com, by clicking through to the international home page.

We have made certain assumptions here, particularly about scholarly content (research, editorials, analysis, and education), which we feel has a more global appeal. Our longer term strategy is to prioritise more research papers from the US, and our acceptance criteria will be very much influenced by readers' feedback (you can tell us what you think by responding to this editorial) and an analysis of which articles get most read in the US, and which generate most debate among readers based there. The ability to "geotarget" articles for the US offers opportunities for readers based elsewhere. We plan to take a similar approach for readers in India and the United Kingdom before the end of 
the year, and we will consider other countries or territories in 2013. It also means that the "edition" of bmj.com seen by readers outside the US, UK, and India can promote the vast number of articles we publish each week that are not about the NHS and healthcare in Britain, although we will continue to promote these if we feel they have international relevance.

Readers will also have the ability to "switch" between editions by clicking on the dropdown menu at the top of all pages. So, for example, a US doctor working in London can see the latest articles on the BMJ USA homepage. Our seven day table of contents (www.bmj.com/archive/sevendays) will continue to provide details of all articles published in the preceding seven days.

Competing interests: Both authors have completed the ICMJE uniform disclosure form at www.icmje.org/coi_disclosure.pdf (available on request from the corresponding author) and declare: no support from any organisation for the submitted work; no financial relationships with any organisations that might have an interest in the submitted work in the previous three years; no other relationships or activities that could appear to have influenced the submitted work.

Provenance and peer review: Not commissioned; not externally peer reviewed.

Audit Bureau of Circulation. www.abc.org.uk/Products-Services/Product-Page/?tid=20259. Deer B. How the case against the MMR vaccine was fixed. BMJ 2011;342:c5347. Cohen D. The truth about sports drinks. BMJ 2012;345:e4737.

Cohen D. How safe are metal-on-metal hip implants? BMJ 2012;344:e1410.

Cohen D. WHO and the pandemic flu "conspiracies." BMJ 2010;340:c2912.

Cite this as: BMJ 2012;345:e6628

(๑) BMJ Publishing Group Ltd 2012 